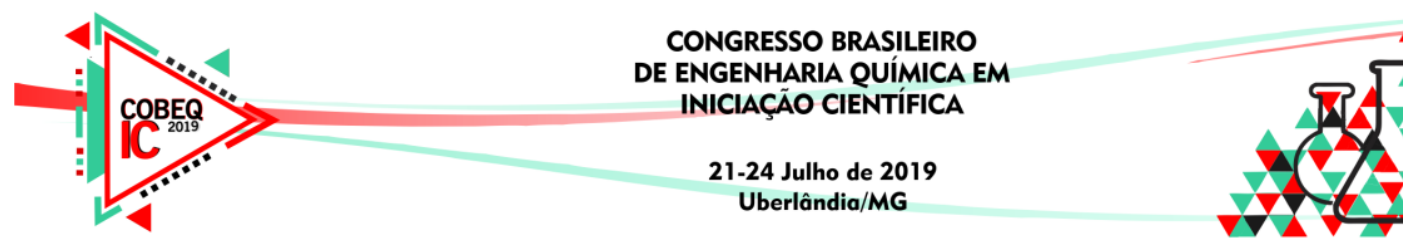

\title{
ESTUDO DA TRANSFERÊNCIA DE CALOR E MASSA NA SECAGEM INFRAVERMELHO COMBINADA COM CONVECÇÃO FORÇADA DO RESÍDUO DA LARANJA
}

\author{
K. S. ANDRADE ${ }^{1}$, L.G. MARQUES ${ }^{1}$ e M. M. PRADO ${ }^{1}$ \\ ${ }^{1}$ Universidade Federal de Sergipe, Departamento de Engenharia Química \\ E-mail para contato: keysinha21@hotmail.com,
}

\begin{abstract}
RESUMO - A elevada produção de resíduos agroalimentares, bem como a necessidade de reduzir a forte dependência das energias não renováveis, tem fomentado o reaproveitamento de resíduos, como biomassa, para geração de energia. Nesse contexto a secagem é uma etapa de pre-tratamento essencial a fim de reduzir a elevada umidade dos materiais orgânicos. Assim, o presente trabalho objetiva avaliar o comportamento da cinética de secagem do resíduo da laranja a partir do estudo transferência de calor e massa na secagem híbrida (infravermelho com convecção forçada). Os experimentos foram realizados com o material particulado em monocamada em condições de ar aquecido e ar ambiente, avaliandose a influência do aquecimento do ar em diferentes velocidades do ar e temperatura da fonte IV. Através dos resultados obtidos, verificou-se que o aquecimento do ar exerceu maior influência para a menor velocidade do ar $(0,4 \mathrm{~m} / \mathrm{s})$ e temperatura da fonte IV $\left(80^{\circ} \mathrm{C}\right)$. Ademais, na menor temperatura da fonte o aumento da velocidade do ar aumentou a taxa de secagem, nos ensaios com e sem aquecimento do ar.
\end{abstract}

\section{INTRODUÇÃO}

O Brasil e o mundo, apesar de várias mudanças na sua matriz energética, ainda são muito dependentes do petróleo. Assim, há uma crescente preocupação com o esgotamento das fontes não renováveis e com a poluição em cadeia. Neste contexto, tem-se o cenário do aproveitamento de resíduos agroalimentares, como biomassa, para produção de energia, tendo em vista a oportunidade de lucro, devido a possibilidade de agregação de valor à um produto final, a partir de resíduos que são uma matéria prima barata e abundante (Costa Filho et al., 2017).

O Brasil ocupa o primeiro lugar na produção de suco de laranja ao nível mundial e, aproximadamente, $60 \%$ dos resíduos gerados acabam sendo desperdiçados, (sementes, casca e bagaço), sendo a casca o componente mais abundante dentre os resíduos (Cano, 2018). Deste modo, a utilização da casca de laranja, como biomassa, para geração de energia é uma alternativa altamente benéfica para o Brasil tanto para redução do acumulo de resíduos no ambiente quanto uma alternativa renovável de energia.

A Empresa de pesquisa energética (EPE) define biomassa, como uma fonte primária de energia renovável, que consiste em matéria orgânica animal ou vegetal e armazena energia em sua forma química, através das ligações de suas moléculas constituintes. A conversão dessa 


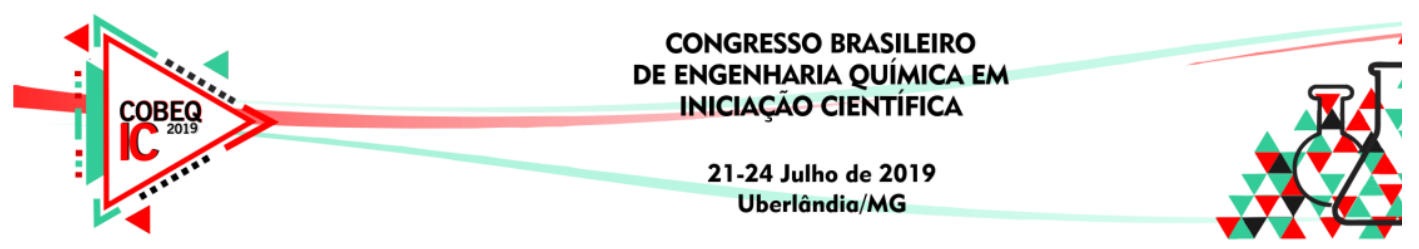

energia constitutiva em energia útil pode ser feita através de pirólise e gaseificação, para produção de bióleo e biogás, respectivamente (Barbosa Neto et al., 2014; Benevides, 2015).

Os resíduos da laranja, bem como a maioria das biomassas, têm altos índices de umidade que limitam a sua aplicação como um combustível alternativo e, portanto, necessitam de uma operação de secagem anterior. Na pirólise, por exemplo, a presença de elevada quantidade de água no início do processo é incorporada pelo produto líquido (Bióleo) ao final, reduzindo sua qualidade (Benevides, 2015). Deste modo, a secagem deve proporcionar a redução da umidade do material, diminuindo custos de armazenamento, transporte e melhorando a conversão química durante o processo de queima para geração de energia

Na literatura é possível encontrar diferentes métodos de secagem. Entre estes, o mais comum na indústria alimentícia é a secagem por convecção forçada de ar aquecido, no entanto apresenta baixa eficiência energética, o que eleva o custo de processo. Outra forma, é a secagem puramente infravermelha (IV) que tem vantagens como, a penetração direta no material sem precisar de um meio material de propagação e, portanto, diminui as perdas de energia no trajeto, resultando em transferências de calor mais eficientes (Adak et al., 2017).

Estudos (Jaturonglumlert e Kiatsiriroat, 2010; Onwude et al, 2018) relatam que o uso combinado da radicação IV com convecção de ar aquecido pode ser mais eficiente que a radiação ou convecção aplicadas de forma isolada, já que a secagem híbrida fornece o efeito sinérgico entre os dois modos. Nesse contexto, o objetivo deste trabalho é avaliar o comportamento da cinética de secagem do resíduo da laranja, analisando a influência da velocidade e aquecimento do ar na secagem híbrida a partir do estudo transferência de calor e massa.

\section{MATERIAS E MÉTODOS}

\subsection{Material}

O bagaço de laranja utilizado foi cedido por restaurantes localizados nas adjacências da Universidade Federal de Sergipe. Após a coleta, os resíduos do endocarpo foram retirados para evitar a formação de aglomerados no decorrer do preparo e a casca foi triturada num liquidificador industrial. A caracterização do material particulado foi feita através do peneiramento, com agitação manual, das peneiras Tyler da BERTE. Após a caracterização, o material, contendo partículas de diâmetro médio de $3,075 \mathrm{~mm}$, foi separado por amostra e acondicionado em refrigerador.

\subsection{Secagem combinada ou híbrida}

O processo de secagem foi executado em secador infravermelho desenvolvido, pelo grupo de pesquisa "Fenômenos de transporte e sistemas particulados" da Universidade Federal de Sergipe. O equipamento, representado na Figura 1, permite a formação de um sistema de secagem híbrida (infravermelho com convecção) com ar em condições ambientes ou aquecido, sendo composto por uma câmara com isolamento térmico e lâmpada de raios infravermelhos (IV) de potência de $250 \mathrm{~W}$. Anexado a câmara tem-se uma cabine que comporta um ventilador, o qual gera o fluxo de ar na câmara . Dentro dessa cabine, foi adicionada uma lâmpada 


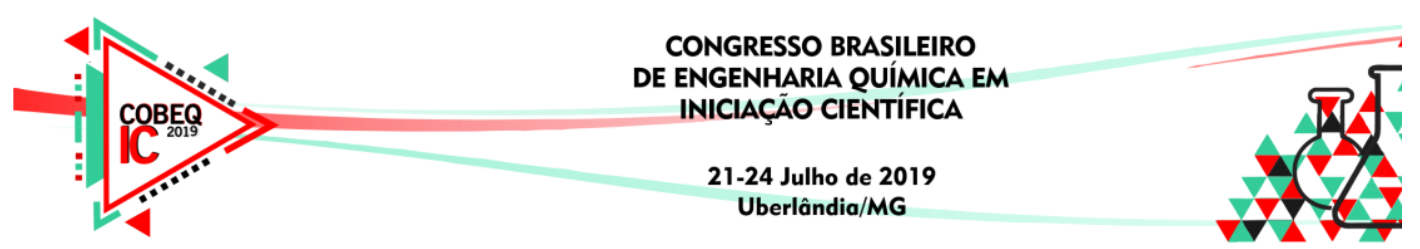

incandescente, de potência $60 \mathrm{~W}$ e tensão $110 \mathrm{~V}$, posicionada entre a entrada de ar e o ventilador, permitindo que o ar seja aquecido ao entrar em contato com a lâmpada.

Figura 1: Visão lateral do equipamento.

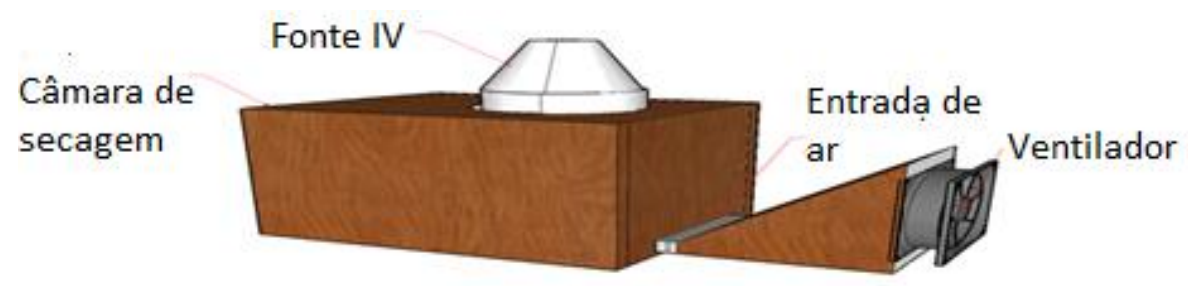

A distância entre a fonte IV e a amostra em monocada foi fixada em $17 \mathrm{~cm}$. As temperaturas da fonte IV foram 80 e $100^{\circ} \mathrm{C}$, medidas através de termopar tipo k localizado próximo a fonte. As velocidades do ar foram 0,4 e $1,0 \mathrm{~m} / \mathrm{s}$, medidas com anemômetro (Instrutherm, modelo Tad 500). Nos ensaios com ar aquecido, a lâmpada incandescente foi mantida na potência máxima e o ar em contato atingiu 49 e $42^{\circ} \mathrm{C}$, para as velocidades 0,4 e 1,0 $\mathrm{m} / \mathrm{s}$, respectivamente. A temperatura do ar foi medida através de termopar do tipo $\mathrm{k}$ localizado próximo a entrada de ar na câmara.

Para a determinação da cinética de secagem da biomassa, foram efetuadas pesagens da amostra em intervalos de tempos pré-definidos, em balança digital (Balança analítica Marte UX420H, Shimadzu, $10^{-6} \mathrm{~kg}$ ). A temperatura da amostra também foi medida ao longo do processo com auxílio de um pirômetro óptico digital (Impac, modelo IP-850, $0,1^{\circ} \mathrm{C}$ ). Este procedimento foi repetido até a massa pesada ficar constante, resultando na estabilidade da umidade da amostra. Ao final, a amostra foi mantida em estufa pré-aquecida a $(105 \pm 3)^{\circ} \mathrm{C}$, durante 24 horas, para obtenção a massa de sólido seco.

A fim de facilitar a análise dos resultados, foi utilizado o adimensional de umidade (XR) dado pela Equação 1:

$$
X R=\frac{X(t)-X e}{X_{0}-X e}
$$

Onde, $\mathrm{Xe}$ e $\mathrm{X}_{0}$ e $\mathrm{X}(\mathrm{t})$ são, respectivamente, teores de umidade de equilíbrio, inicial e em um dado instante de tempo.

\section{RESULTADOS E DISCUSSÕES}

As Figuras 2 e 3 representam as curvas do adimensional de umidade (XR) e temperatura da amostra ( $\mathrm{T}$ ) em função do tempo, para os ensaios com ar aquecido e ar ambiente na temperatura da fonte IV ( $\left.\mathrm{T}_{\mathrm{IV}}\right)$ em $80^{\circ} \mathrm{C}$ e velocidades do ar $\left(\mathrm{V}_{\mathrm{ar}}\right)$ em 0,4 e $1,0 \mathrm{~m} / \mathrm{s}$, respectivamente. Na Figura $2\left(\mathrm{~V}_{\mathrm{ar}}=0,4 \mathrm{~m} / \mathrm{s}\right)$, é possível observar que o aquecimento do ar conduziu à maiores temperaturas na amostra $\left(60^{\circ} \mathrm{C}\right)$ em comparação com o ar não aquecido $\left(50^{\circ} \mathrm{C}\right)$, provocando um aumento na taxa de secagem e por conseguinte reduzindo o tempo necessário para atingir o teor de equilíbrio , de 140 para $100 \mathrm{~min}$, nos ensaios com ar ambiente e ar aquecido, respectivamente. Isso foi resultado do aumento da transferência de calor e massa, causado pelo maior gradiente de temperatura entre a amostra e o ar, visto que o ar aquecido 


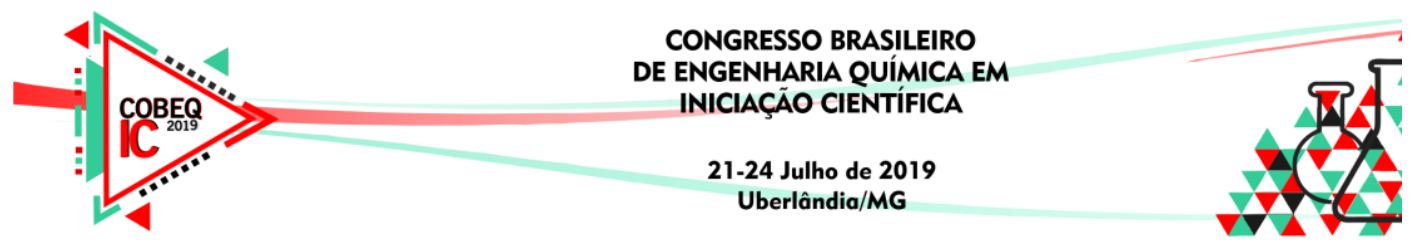

atingiu $49^{\circ} \mathrm{C}$ e o ar ambiente $26^{\circ} \mathrm{C}$. Em consequência do aumento da temperatura, a umidade relativa do ar é menor, aumentando a força motriz de transferência de massa e portanto a capacidade do ar de remover a água superficial do material (Pesk et al.,2003).

Figura 2 - Adimensional de umidade e temperatura em função do tempo à $80^{\circ} \mathrm{C} \mathrm{e}$ $0,4 \mathrm{~m} / \mathrm{s}$.

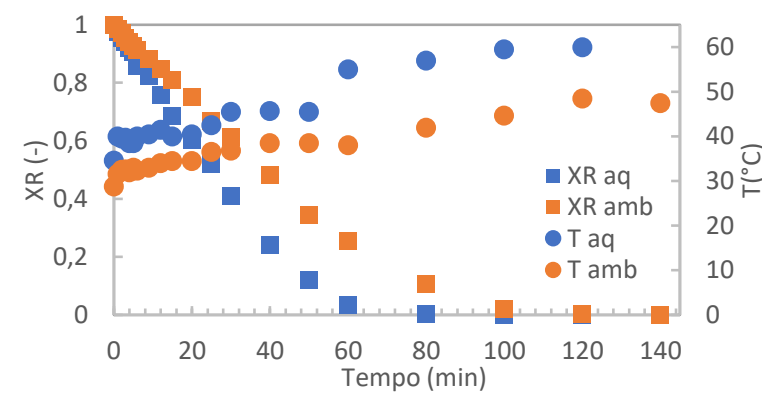

Figura 3 - Adimensional de umidade e temperatura em função do tempo à $80^{\circ} \mathrm{C} \mathrm{e}$ $1,0 \mathrm{~m} / \mathrm{s}$.

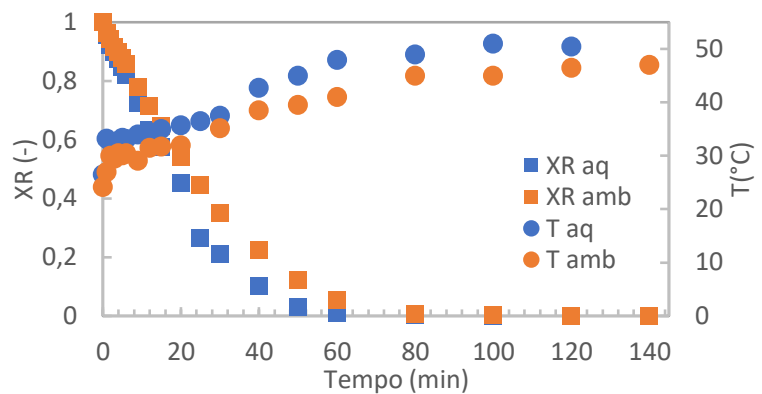

Quando a velocidade do ar é aumentada para $\mathrm{V}_{\mathrm{ar}}=1,0 \mathrm{~m} / \mathrm{s}$, Figura 3, observa-se um comportamento análogo à Figura $2\left(\mathrm{~V}_{\mathrm{ar}}=0,4 \mathrm{~m} / \mathrm{s}\right)$, ou seja, para o ar aquecido obtém-se maiores temperaturas e taxas de secagem e menores tempos de secagem, visto que as amostras atingiram o teor de equilíbrio em 80 e 100 min para os ensaios com ar aquecido e ar ambiente, respectivamente. Porém, a resposta do material com o aquecimento do ar não é tão expressiva quanto o observado à $0,4 \mathrm{~m} / \mathrm{s}$, pois o aumento da velocidade do ar provoca uma diminuição na sua temperatura devido às características inerentes ao sistema de convecção. Como a lâmpada incandescente dentro da cabine de convecção é responsável pela geração de calor, através da conversão de energia luminosa em calor, o ar que entra em contato com essa lâmpada é aquecido durante seu trajeto. Assim, o ar à $1,0 \mathrm{~m} / \mathrm{s}$, o qual possui um menor tempo de residência dentro da cabine, aquece menos, chegando à amostra com menores temperaturas $\left(39^{\circ} \mathrm{C}\right)$ quando comparado com à temperatura de $49^{\circ} \mathrm{C}$ para $\mathrm{V}_{\mathrm{ar}}=0,4 \mathrm{~m} / \mathrm{s}$. Portanto, a diferença entre a temperatura do ar aquecido e o ar ambiente é menor, e consequentemente a influência do aquecimento é reduzida.

No entanto, ao analisar o aquecimento do ar para as diferentes velocidades (curvas em azul), verifica-se que, quando a velocidade aumenta de 0,4 para $1,0 \mathrm{~m} / \mathrm{s}$, o tempo de secagem diminui de 100 para 80 min, como pode ser observado nas Figuras 2 e 3. Isso porque o aumento da velocidade do ar provocou maior turbulência no escoamento, elevando o coeficiente de transferência de calor por convecção, e, portanto, a taxa de secagem. Além disso, a transferência de massa externa é favorecida pois o aumento da velocidade facilita a remoção de umidade da superfície do material. Analisando somente a condição de ar ambiente (curvas em laranja), percebe-se um comportamento similar, obtendo tempos de secagem de 140 e 100 min para $\mathrm{V}_{\text {ar }}$ $=0,4$ e $1,0 \mathrm{~m} / \mathrm{s}$, respectivamente, evidenciando a influência da velocidade na transferência de massa por convecção mesmo não havendo aquecimento do ar.

Quando a $\mathrm{T}_{\mathrm{IV}}$ aumenta para $100^{\circ} \mathrm{C}$, Figuras 4 e 5, os ensaios de secagem de forma geral são mais rápidos $(50 \mathrm{~min})$ frente aos ensaios à $80^{\circ} \mathrm{C}$, cujo o tempo mínimo foi $80 \mathrm{~min}$. Esse comportamento era esperado, pois ocorre o aumento da absorção de radiação IV pelas 


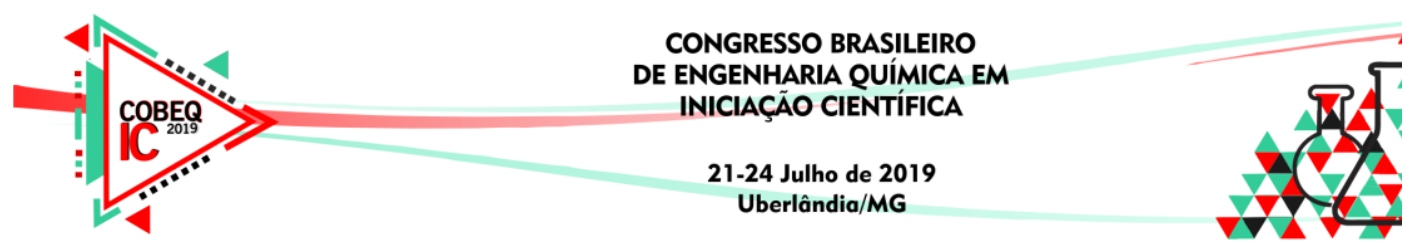

moléculas de água, causando elevação da taxa de condução de calor dentro das partículas e, por conseguinte, uma rápida difusão da umidade para a superfície (Onwude et al., 2018).

Figura 4 - Adimensional de umidade e temperatura em função do tempo á $100^{\circ} \mathrm{C}$ e $0,4 \mathrm{~m} / \mathrm{s}$.

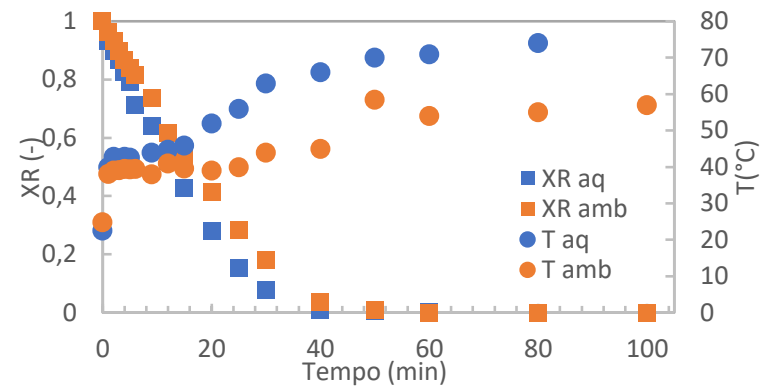

Figura 5 - Adimensional de umidade e temperatura em função do tempo à $100^{\circ} \mathrm{C} \mathrm{e}$ $1,0 \mathrm{~m} / \mathrm{s}$.

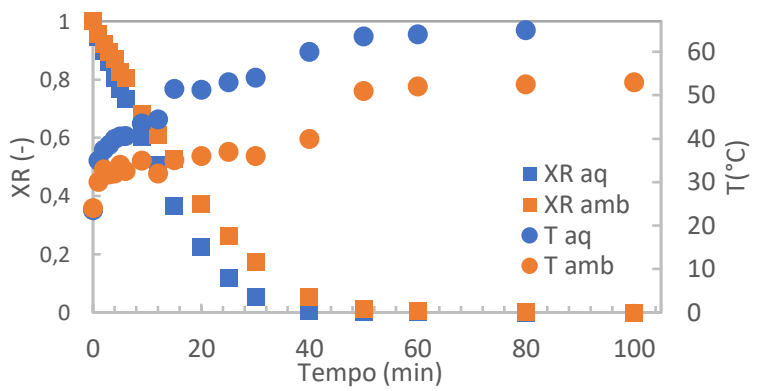

Analisando os resultados apresentados nas Figuras 4 e 5, nota-se que a influência exercida pelo aquecimento do ar é similar. Assim para as duas velocidades, o aquecimento do ar provocou aumento da temperatura da amostra, porém um pequeno aumento na taxa de secagem. Ademais, o aumento da velocidade na condição de aquecimento (curvas em azul) não modificou o tempo de secagem. Esses resultados se justificam pois, em maiores $T_{I V}$ a transferência de calor por radiação predomina frente à transferência de calor por convecção e, portanto, variações na temperatura e velocidade do ar não geram influencias significativas.

Comparando a influência do aquecimento do ar entre os ensaios de $\mathrm{T}_{\mathrm{IV}}=80$ e $100^{\circ} \mathrm{C}$, fixando $\mathrm{V}_{\mathrm{ar}}=0,4 \mathrm{~m} / \mathrm{s}$, percebe-se, através das Figuras 2 e 3 , que à $100^{\circ} \mathrm{C}$ há uma influência menos significativa que à $80^{\circ} \mathrm{C}$. Isso pode ser explicado através da análise das curvas de taxa de secagem nas mesmas condições, representadas pelas Figuras 6 e 7. Para $T_{I V}=80^{\circ} \mathrm{C}$ ( Figura 6) a taxa de secagem com ar aquecido (curva em azul) permanece maior em relação a secagem com ar ambiente (curva em laranja) durante $40 \mathrm{~min}$, porém em $\mathrm{T}_{\mathrm{IV}}=100^{\circ} \mathrm{C}$ (Figura 7) esse tempo é reduzido. Assim, o aquecimento do ar exerce maior influência em menores intensidade de radiação $\left(\mathrm{T}_{\mathrm{IV}}=80^{\circ} \mathrm{C}\right)$ pois o fenômeno de transferência de calor por convecção é mais significativo em menores velocidades e temperaturas da fonte IV, e, portanto, a resposta do sistema às mudanças nas condições do ar é mais expressiva.

Figura 6 - Taxa de secagem em função do tempo à $80^{\circ} \mathrm{C}$ e $0,4 \mathrm{~m} / \mathrm{s}$.

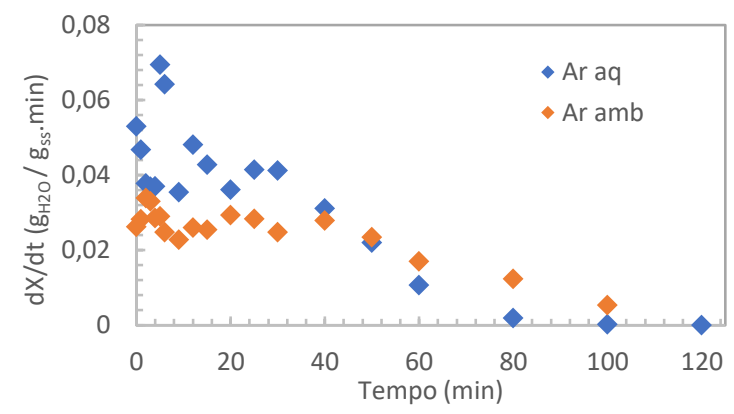

Figura 7 - Taxa de secagem em função do tempo à $100^{\circ} \mathrm{C}$ e $0,4 \mathrm{~m} / \mathrm{s}$.

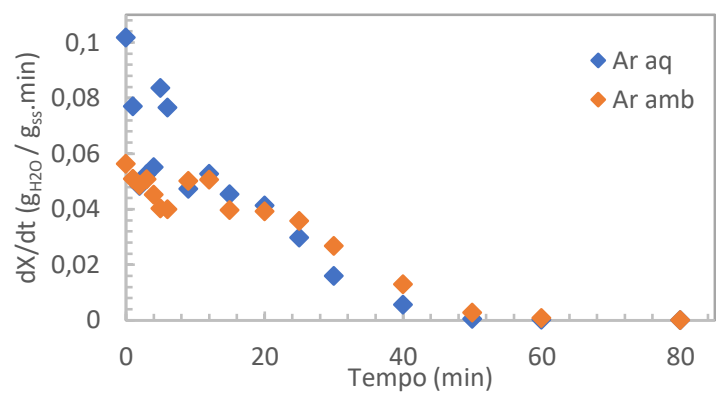




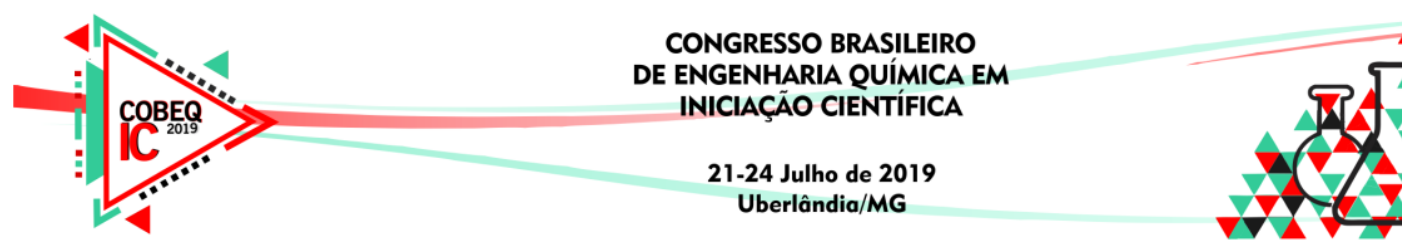

Estudos realizados por Jaturonglumlert e Kiatsiriroat (2010), sobre a secagem híbrida, concluíram que o aumento da velocidade do ar provoca um aumento no coeficiente convectivo de massa frente ao coeficiente convectivo de calor. Adak et al (2017), estudou a influência da TIV e Var, obtendo maiores taxas de secagem, com aumento destas variáveis. Já o trabalho de Owude et al (2019) concluiu que a elevação da $T_{I V}$ aumenta a difusividade efetiva do material e, portanto, a taxa de secagem. Esses estudos corroboraram positivamente com os resultados apresentados pelo presente documento, conferindo maior validade aos mesmos.

\section{CONCLUSÕES}

$\mathrm{O}$ aumento da $\mathrm{T}_{\mathrm{IV}}$ diminuiu os tempos de secagem, como esperado. $\mathrm{O}$ aquecimento do ar aumentou as taxas de secagem, exercendo maior influência em menores intensidades de radiação $\left(\mathrm{T}_{\mathrm{IV}}=80^{\circ} \mathrm{C}\right)$ e de velocidades do ar, evidenciando a predominância do fenômeno de transferência de calor por convecção frente à radiação. A influência do aquecimento do ar foi menos expressiva para $\mathrm{V}_{\mathrm{ar}}=1,0 \mathrm{~m} / \mathrm{s}$, pois o ar atingiu uma menor temperatura, quando comparada com a temperatura atingida à $\mathrm{V}_{\mathrm{ar}}=0,4 \mathrm{~m} / \mathrm{s}$, devido ao menor tempo de contato com a lâmpada incandescente. $\mathrm{O}$ aumento da velocidade do ar, para $\mathrm{T}_{\mathrm{IV}}=80^{\circ} \mathrm{C}$, diminuiu os tempos de secagens tanto para os ensaios com ar aquecido quanto com ar ambiente, evidenciando a influência da transferência de calor e massa por convecção.

\section{REFERÊNCIAS}

ADAK, N.; HEYBEILI, N.; ERTEKIN, C. Infrared drying of strawberry. Food Chem 219, p. 109-116, 2017.

BARBOSA NETO, A. M.; LIMA, J. O.; MARQUES, L. G.; PRADO, M. M. Secagem infravermelho de caroços de açaí para a obtenção de biomassa. XX Congresso Brasileiro de Engenharia Química. Florianópolis - SC, 2014.

BENEVIDES, L. C.; Pirólise do bagaço de laranja: análise cinética dos estágios de secagem e devolatização. Dissertação (Mestrado em Energia, na área de concentração Engenharia, Tecnologia e Gestão) - Universidade Federal do Espírito Santo, São Mateus - ES, 2015.

CANO, N. D.; Produção de metano a partir do licor pré-tratado obtido da casca de laranja em reator anaeróbio em batelada. Dissertação (Mestrado em Engenharia Agrícola) Universidade Estadual de Campinas, Campinas - SP, 2018.

COSTA FILHO, D. V.; SILVA, A. J.; SILVA, P. A. P. SOUSA, F. C. Aproveitamento de resíduos agroindustriais na elaboração de subprodutos .II Congresso Nacional das Ciencias Agrárias , 2017.

JATURONGLUMELERT, S; KIATSIRTOAT, T; Heat and mass transfer in combined convective and far-infrared drying of fruit leather. Journ of Food Eng, n100, p254-260

ONWUDE, D.; HASHIMA, M.; ABDANA, K.; JANIUS,G.; CHEN, G .The efectiveness of combined infrared and hot-air drying strategies for sweet potato. Journ of Food Eng , [S.1.], n. 241, p. 75-87, 2019.

PESK, S. T.; VILLELA, F. A. Secagem de Sementes. In: sementes: fundamentos científicos e tecnológicos, ed. pesk, s.t; rosenthal, m.a; rota , chapter 5. 2003. 415p. 